\title{
Diretrizes para implantação de um sistema de saúde e segurança do trabalho em empresas produtoras de álcool em gel
}

\section{Guidelines for implementing an occupational health and safety system in companies producing alcohol-based hand sanitizer}

\author{
${ }^{1}$ Daniel Ippolito Pelufo, ${ }^{2}$ Luciane Cleonice Durante \\ ${ }^{1}$ Engenheiro Químico, Mestre em Química Analítica Ambiental pela Universidade Federal de Mato Grosso \\ (pelufodaniel@gmail.com.br) \\ ${ }^{2}$ Doutora em Conforto Ambiental, Professor Associado do Departamento de Arquitetura e Urbanismo da \\ Faculdade de Arquitetura, Engenharia e Tecnologia da Universidade Federal de Mato Grosso \\ (luciane.durante@hotmail.com)
}

\begin{abstract}
RESUMO: O súbito aumento da demanda por higienizantes e sanitizantes, ocasionado pela pandemia de COVID-19, desencadeou um crescente aumento no número de empresas produtoras de sanitizantes para as mãos, principalmente, álcool em gel. Dificuldades na elaboração, desenvolvimento e operação do processo produtivo, aliado à insegurança dos colaboradores no desempenho de suas atividades podem ser desafios que interferem na capacidade destes empreendimentos em produzir processos, produtos e um ambiente de trabalho de qualidade. Dentro deste contexto, os sistemas de saúde e segurança do trabalho podem desempenhar um papel fundamental no posicionamento estratégico e no desenvolvimento sustentável de uma empresa, além de contribuir para motivação e bem estar de seus colaboradores, gerando bons resultados e competitividade. Este trabalho teve como objetivo elaborar diretrizes para implantação de um sistema de saúde e segurança do trabalho voltado para o processo produtivo de álcool em gel e para o manuseio das matérias primas utilizadas no processo. Para tanto, um estudo de caso foi realizado em uma fábrica deste sanitizante, utilizando-se da metodologia da Análise Preliminar de Risco. O estudo demonstrou que o álcool, o polímero e o neutralizante utilizados na produção devem receber atenção e o processo produtivo deve se adaptar à natureza destas substâncias. Além disto, a etapa do processo produtivo denominada elaboração do álcool em gel, deve obedecer a procedimentos quanto ao armazenamento e o manuseio das matérias primas, que são determinantes para gerar uma produção eficiente e segura.
\end{abstract}

Palavras-chave: Análise Preliminar de Risco. Segurança do Trabalho. Riscos ocupacionais.

ABSTRACT: The production of hand sanitizers has increased considerably in recent times, mainly due to the COVID-19 pandemic experienced by the world. Many organizations are struggling difficulties in implementing and operating alcohol-based sanitizer production processes, due to the specificities of both the flammable liquid and the other raw materials used in the production process. Occupational health and safety systems can play a fundamental role in the strategic positioning and sustainable development of a company, in addition to contributing to the motivation and well-being of its employees, generating good results and competitiveness. The main goal of this work was to formulate guidelines for the implantation of a health and safety system focused mainly on the productive process of alcohol in gel, for this, a case study was carried out in a sanitizer factory. The study demonstrated that the alcohol, polymer and neutralizer used in production must be viewed carefully and the production process must adapt to the nature of these substances. In addition, the stage of elaboration of the production process must elaborate procedures and take special care in the form of storage and handling of raw materials, as these areas of the process are crucial to generate an efficient and safe production.

Keywords: Preliminary risk analysis. Workplace safety. Occupational risks.

\section{INTRODUÇÃO}

Um sanitizante para as mãos pode ser definido como um líquido, gel ou espuma que, geralmente, é produzido a partir de etanol, álcool isopropílico, ou uma mistura destes álcoois, e tem como principal função limpar as mãos e reduzir, significantemente, a quantidade de microrganismos causadores de doenças. A eficiência na redução de microrganismos destes sanitizantes está diretamente relacionada a concentração do álcool em sua composição. 
Pesquisas recentes evidenciaram que sanitizantes contendo entre 50 a $70 \%$ de álcool são mais eficientes do que aqueles contendo álcool a 95\%. Além disso, estes estudos também indicam que a melhor concentração para o uso na descontaminação das mãos é o álcool contendo $70 \%$ em massa, visto que a camada proteica que envolve os microrganismos causadores de doenças é desnaturada de forma mais eficiente nesta concentração, pois a água tem papel fundamental neste mecanismo (BOYCE, 2000; TODD et al., 2010).

A Organização Mundial da Saúde (OMS), desde o princípio da pandemia ocasionada pelo novo corona vírus, SARSCoV2, recomenda o uso de sanitizantes a base de álcool para higienização das mãos, visto que este é o principal método para prevenir a doença COVID-19, antes do surgimento de uma vacina. Por esta razão, grandes quantidades de sanitizantes para as mãos vêm sendo demandado pela sociedade e, não só no Brasil, mas como no mundo, o álcool gel é um dos principais sanitizantes utilizados para esta finalidade (TOLEDO, 2020).

Segundo o presidente da Associação Brasileira da Indústria de Higiene Pessoal, Perfumaria e Cosmético - ABIHPEC, estimativa de consumo do álcool em gel em 2020, por causa da pandemia do Covid19, poderá superar em até 10 vezes o valor registrado em 2019 (BASILIO, 2020).

Para solucionar o problema de desabastecimento a Agencia Nacional de Vigilância Sanitária - ANVISA, emergencialmente, editou a Resolução da Diretoria Colegiada - RDC n. ${ }^{\circ}$ 350, de 19 de março de 2020, que autoriza, em caráter excepcional e temporário, que empresas fabricantes de medicamentos, cosméticos e saneantes regularizadas fabriquem e comercializem várias preparações antissépticas sem a prévia autorização do órgão (BRASIL, 2020).

O álcool em gel pode ser obtido por vários métodos dependendo da matéria prima utilizada na sua produção, no entanto, o princípio geral do seu preparo é baseado na mistura de álcool, água e um polímero que tem a função de gelificar a mistura deixando-a mais densa, com a consistência de gel, o que é característico deste sanitizante.

A característica de gel que o polímero traz ao sanitizante, deriva de um conceito conhecido como dispersão coloidal, quando adicionamos partículas pequenas em uma solução, a ponto de não serem vistas a olho nu, dizemos que esta solução é coloidal ou, simplesmente, coloides. Estas partículas coloidais possuem tamanho médio de 1 nanômetros a 1 micrometro e permanecem em suspensão, por este motivo, os coloides possuem propriedades intermediárias entre solução e suspensão (EVERETT, 2009).

Ainda dentro do conceito de coloides, temos os sóis e os géis, sol refere-se a dispersão de uma substância sólida em um líquido e o gel é uma rede coloidal não fluida ou uma rede coloidal expandida por um fluido, podemos citar como exemplo, a gelatina que assume o papel tanto de sol, como de gel. Quando o pó de preparo é adicionado à água quente, a gelatina possui característica de sol e quando é resfriada passa a ter propriedades de gel, além da gelatina, precipitados dos hidróxidos de $\mathrm{Al}+3, \mathrm{Fe}+3, \mathrm{Cu}+2$ também são exemplos de géis (ATKINS E JONES, 2012).

O álcool em gel vem sendo um dos principais higienizastes para mãos, devido, principalmente, pela sua praticidade e por ter um tempo de ação maior quando comparado ao líquido que evapora facilmente. A sua formulação geralmente utiliza etanol $96 \%(\mathrm{v} / \mathrm{v})$, solução de trietanolamina a $5 \%(\mathrm{p} / \mathrm{v})$ como neutralizante, água purificada e um polímero gelificante. Este gelificante tem como função dar o aspecto de gel a solução, sua estrutura química possui grupamentos químicos como $-\mathrm{OH}$ ou $\mathrm{COOH}$, que estabelecem interações intermoleculares com o etanol e a água, dando boa estabilidade ao gel formado (ANVISA, 2012; SEQUINEL et al., 2020).

Comercialmente, o principal gelificante utilizado é um carbômero conhecido como carbopol, descrito no Formulário Nacional da Farmacopeia Brasileira como carbômer 980, os carbômeros são polímeros de ácidos poliacrílicos, contendo entre 56 e $68 \%(\mathrm{~m} / \mathrm{m})$ de ácidos 
carboxílicos $(\mathrm{COOH})$ e alto peso molecular entre 7 x 105 a 4x109 g/mol (SEQUINEL et al., 2020).

Devido à grande procura em virtude da pandemia, este carbômero tornou-se escasso no mercado, algumas alternativas são sugeridas para sua substituição, como por exemplo, a hidroxipropilmetilcelulose que é um pó branco ou ligeiramente amarelado, inodoro, insípido e atóxico. Pode ser dissolvido em água fria para formar uma solução transparente e viscosa. $\mathrm{O}$ Polyquaternium-37, um polímero catiônico também na forma de pó que proporciona excelente viscosidade a sistemas com alta carga de eletrólitos e o hidroxietilcelulose outro polímero solúvel em água, especialmente modificado, não iônico, obtido da reação de óxido de etileno com celulose alcalina. Solúvel em água fria ou quente, forma soluções cristalinas de viscosidade variável (MAGALHÃES, 2020).

O limitante para utilização destas alternativas está no aumento do custo de produção e, consequentemente, o aumento do preço do produto. Por este motivo, alternativas vêm sendo exploradas, um estudo realizado pela Empresa Brasileira de Pesquisa Agropecuária (EMBRAPA) produziu álcool em gel a partir de nanocelulose mecanicamente desfibrilada (MFC), obtido a partir das espécies de madeira Pinus e eucalipto, segundo os pesquisadores, esta formulação é uma alternativa mais barata, visto que a matéria prima é facilmente disponível no mercado (MAGALHÃES; DEGENHARDT, 2020).

A crescente demanda por álcool em gel, levou muitas fábricas a se reequiparem e mudar suas operações para atender este súbito aumento na procura. Existem, também, muitas fabricas sendo montadas às pressas, além de pequenas plantas que surgem de projetos sociais fomentados pelo governo.

Muitas cervejarias não só no Brasil, mas também em todo o mundo fizeram readequações em seus processos durante para produzir sanitizantes para as mãos, principalmente, álcool etílico líquido a $70 \%(\mathrm{~m} / \mathrm{m})$ (CORRÊIA, 2020; FOLHA DE PERNAMBUCO, 2020).

Thomson e Bullied (2020) descreveram os meios utilizados para adaptar instalações de produção de cerveja para produzir sanitizantes para as mãos, considerando, principalmente, qualidade e segurança nas operações. Os autores reportam que é importante observar detalhadamente todas as normas e legislações governamentais do local, bem como os especialistas em segurança, principalmente para as questões de transporte do produto, volumes e forma de envase, além dos meios de armazenamento do produto acabado e matéria prima, visto que lidar com álcool etílico envolve grande risco de explosão.

Os autores também argumentam sobre a necessidade de mapear o processo produtivo em busca de possíveis pontos de ignição, para isto a avaliação considera crítico os locais do processo onde os três agentes de risco estão presentes: álcool, oxigênio e fontes de ignição.

Devido a urgência em atender a população, muitas organizações podem estar usando equipamentos que não foram projetados para manipular produtos químicos perigosos ou inflamáveis, além de fazer armazenamento sem observar o risco associado, expondo os seus colaboradores a perigos, e estes, muitas vezes, não possuem treinamento para lidar com esta classe de produtos (JENKINS, 2020).

O álcool em gel possui em sua composição grande quantidade de etanol, composto que é extremamente inflamável e que pode causar irritações a pele, segundo a NBR 14725- 2 (ABNT,2009), este líquido combustível é classificado como sendo da categoria 2 de perigo, visto que seu ponto de fulgor é de $13^{\circ} \mathrm{C}$, ou seja, a partir desta temperatura o etanol começa e liberar vapores que, em contato com fontes de calor, têm possibilidade de entrar em combustão. Este baixo ponto de fulgor pode também gerar riscos quando manipulado em ambientes fechados, devido ao acúmulo de gases, aumentado a probabilidade de explosões.

O trabalho com produtos perigosos, como etanol, aliado a todos os riscos ambientais comuns em linhas de produções, pode gerar um grande aumento no número de acidentes de 
trabalho fatais. Portanto, a identificação destes riscos no ambiente e adequação destas fabricas produtoras de sanitizantes a critérios de segurança do trabalho adequados é fundamental para evitar perdas materiais expressivas e, principalmente, evitar acidentes envolvendo vidas humanas.

Dentro deste contexto, a implantação de um sistema de gerenciamento de segurança e saúde no trabalho (SGSST) pode enfrentar muitas dificuldades, desta forma, o planejamento antecipado aliado a instrumentos e técnicas, surge como forma de minimizar problemas ao pôr em prática o SGSST.

Mediante o exposto, este artigo tem como principal objetivo apresentar diretrizes, baseadas em referencial teórico e nos resultados de um estudo realizado em uma fábrica de produção de álcool em gel, os quais poderão ser tomados como um ponto de partida para implantação de um sistema de segurança e saúde no trabalho.

\section{MÉTODO}

Este trabalho foi organizado seguindo a metodologia de estudo de caso, por meio de pesquisa qualitativa. Esta categoria de pesquisa busca estudar as particularidades e complexidades de um caso singular, levando a entender sua atividade dentro de importantes circunstâncias ou contexto, com isso, o estudo de caso pode oferecer a possibilidade de uma visão profunda e ao mesmo tempo ampla e integrada, fornecendo informações valiosas que podem ser empregadas como ferramentas para decisões estratégicas (YIN, 2001).

A escolha da fábrica se deu devido, principalmente, ao contexto atual vivido pela sociedade e a importância do tipo de atividade na contribuição de construção de conhecimento na área da saúde e segurança no trabalho e, por consequência, na formulação das diretrizes propostas neste estudo.

A coleta de dados foi realizada através de observação in loco (visita à planta de produção e participação em reuniões da alta direção), análise de documentos (procedimentos, práticas adotadas e registros etc.) e entrevistas com os colaboradores, principalmente da área de produção.

\subsection{Análise Preliminar de Risco (APR)}

A APR será utilizada com objetivo de identificar e avaliar preliminarmente acontecimentos inseguros, suas causas ou fontes dentro do processo de produção de álcool em gel da fábrica em estudo. Esta avaliação permitirá identificar os pontos críticos do processo produtivo e, consequentemente, auxiliará na elaboração de diretrizes específicas que, possivelmente, são típicas da produção de álcool em gel.

A ferramenta de análise preliminar de risco (APR) é utilizada com frequência quando há o interesse em determinar os riscos que poderão estar presentes nas etapas operacionais de um processo, por esta razão, a APR tem seu foco voltado para a identificação de acontecimentos inseguros, causas e resultados, além de determinar meios de controle (TAVARES, 2016).

A Categorização dos riscos foi elaborada baseando-se na Norma Técnica Petrobras NT-2782, sendo que a denominação dos riscos como sendo Moderado, Tolerável e Não Toleráveis são resultantes da matriz frequência x severidade.

A tabela 1 mostra a conceituação de frequência tipicamente utilizada na construção da APR. 
Pelufo, D.I.; Durante, L.C.; Diretrizes para implantação de um sistema de saúde e segurança do trabalho em empresas produtoras de álcool em gel. E\&S - Engineering and Science, 2021, 10.

Tabela 1 - Tabela de frequência utilizada na construção da APR.

\begin{tabular}{|c|c|c|c|}
\hline \multicolumn{2}{|c|}{ Categoria } & Frequência & Descrição \\
\hline A & $\begin{array}{l}\text { Extremamente } \\
\text { remoto }\end{array}$ & $<1 \mathrm{EM} 10^{5}$ ANOS & $\begin{array}{l}\text { Conceitualmente possível, mas } \\
\text { extremamente improvável de } \\
\text { ocorrer durante a vida útil do } \\
\text { empreendimento. Sem } \\
\text { referências históricas de que isto } \\
\text { tenha ocorrido. }\end{array}$ \\
\hline B & remoto & $\begin{array}{c}1 \mathrm{EM} 10^{3} \text { ANOS A } 1 \text { EM } 10^{5} \\
\text { ANOS }\end{array}$ & $\begin{array}{l}\text { Não esperado ocorrer durante a } \\
\text { vida útil da instalação, apesar de } \\
\text { haver referências históricas. }\end{array}$ \\
\hline $\mathrm{C}$ & Pouco provável & $\begin{array}{c}1 \text { EM } 30 \text { ANOS A } 1 \text { EM } 10^{3} \\
\text { ANOS }\end{array}$ & $\begin{array}{l}\text { Possível de ocorrer até uma vez } \\
\text { durante a vida útil da instalação. }\end{array}$ \\
\hline $\mathrm{D}$ & provável & 1 POR ANO A 1 EM 30 ANOS & $\begin{array}{c}\text { Esperado ocorrer mais de uma } \\
\text { vez durante a vida da instalação. }\end{array}$ \\
\hline $\mathrm{E}$ & frequente & $>1$ POR ANO & $\begin{array}{l}\text { Esperado ocorrer muitas vezes } \\
\text { durante a vida útil da instalação. }\end{array}$ \\
\hline
\end{tabular}

Fonte: Adaptado da Norma Técnica Petrobras NT-2782 e TAVARES, 2016.

A frequência utilizada no trabalho foi baseada, parte em frequências utilizadas em atividades de outras organizações que lidam com manuseio e armazenamento de combustíveis e líquidos inflamáveis similares, como por exemplo, postos de combustíveis e outra parte através de observação em loco e entrevista com os colaborares da área de produção da fábrica (PETROBRAS, 2010).

Ainda de acordo com a metodologia utilizada, os cenários de acidente são classificados em categorias de severidade, as quais fornecem uma indicação qualitativa do grau de severidade das consequências de cada um dos cenários identificados. A tabela 2 mostra o conceito utilizado para classificar a severidade.

Tabela 2 - Tabela de severidade utilizada na construção da APR.

\begin{tabular}{c|c|c|c|c}
\hline \multicolumn{2}{c|}{ Categoria } & Segurança pessoal & Instalações & Imagem \\
\hline I & Desprezível & $\begin{array}{c}\text { Sem lesões ou no máximo } \\
\text { caso de primeiros } \\
\text { socorros em afastamento. }\end{array}$ & $\begin{array}{c}\text { Sem danos ou danos } \\
\text { insignificantes aos } \\
\text { equipamentos. }\end{array}$ & Sem Impacto \\
\hline II & marginal & $\begin{array}{c}\text { Lesões leves em } \\
\text { funcionários e terceiros. } \\
\text { Ausência de Lesões } \\
\text { extramuros. }\end{array}$ & $\begin{array}{c}\text { Danos leves aos } \\
\text { equipamentos ou } \\
\text { instalações. }\end{array}$ & Impacto Local \\
\hline III & Crítica & $\begin{array}{c}\text { Lesões de gravidade } \\
\text { moderada em pessoas } \\
\text { intramuros. Lesões leves } \\
\text { em pessoas extramuros. }\end{array}$ & $\begin{array}{c}\text { Danos severos a } \\
\text { equipamentos ou } \\
\text { instalações. }\end{array}$ & Impacto \\
Regional
\end{tabular}

Fonte: Adaptado da Norma Técnica Petrobras NT-2782 e TAVARES, 2016. 
Pelufo, D.I.; Durante, L.C.; Diretrizes para implantação de um sistema de saúde e segurança do trabalho em empresas produtoras de álcool em gel. E\&S - Engineering and Science, 2021, 10.

Para construção da matriz de risco que apresenta uma indicação qualitativa do nível de cada cenário identificado na análise, faz-se então, a combinação da frequência com a severidade. A tabela 3 mostra a matriz risco utilizada na construção da APR.

Tabela 3 - Matriz de risco utilizada na construção da APR.

\begin{tabular}{c|c|c|c|c|c}
\hline & $\mathbf{A}$ & $\mathbf{B}$ & $\mathbf{C}$ & $\mathbf{D}$ & $\mathbf{E}$ \\
\hline IV & Moderado & Moderado & Não tolerável & Não tolerável & Não tolerável \\
\hline III & Moderado & Moderado & Moderado & Não tolerável & Não tolerável \\
\hline II & Tolerável & Tolerável & Moderado & Moderado & Moderado \\
\hline I & tolerável & Tolerável & Tolerável & Tolerável & Moderado \\
\hline
\end{tabular}

Fonte: Adaptado da Norma Técnica Petrobras NT-2782 e TAVARES, 2016.

Com as informações obtidas através da matriz de risco foi possível classificar as atividades estudadas e montar a APR.

\subsection{Composição do Álcool em Gel}

O álcool em gel é, basicamente, uma mistura de álcool, água e um polímero que tem a função de gelificar o meio. O Formulário Nacional da Farmacopeia Brasileira $2^{\circ}$ edição de 2011 apresenta uma composição típica para o produto, conforme Tabela 4.

Tabela 4 - Composição do álcool em gel 70\% INPM.

\begin{tabular}{c|c}
\hline Componentes & Quantidades \\
\hline Álcool etílico $96 \mathrm{GL}$ & $75,73 \mathrm{~g}$ \\
\hline Carbômer 980 & $0,5 \mathrm{~g}$ \\
\hline Solução de trietanolamina $50 \%(\mathrm{p} / \mathrm{v})$ & $\mathrm{qs}$ \\
\hline Água purificada qsp* & $100 \mathrm{~g}$ \\
\hline
\end{tabular}

* Quantum satis para ou quantidade suficiente para.

Para a fabricação do produto, a fábrica de álcool em gel adquire álcool $96^{\circ} \mathrm{GL}$ de cana de açúcar diretamente dos produtores, o qual vem armazenado em containers IBC (Intermediate Bulk Conteiner) de mil litros, organizados de forma a ter uma capacidade total de estocagem de 10 mil litros. Os containers IBC foram todos aterrados para prevenir centelhas nas operações de descarga de álcool e foram alocados em espaço com boa circulação de correntes de ar.

Devido à grande procura, o polímero utilizado como matéria prima mais comum, Carbômero 980, encontrava-se em falta no mercado, por este motivo, durante o período da pesquisa de campo, observou-se a utilização de três tipos de polímeros diferentes para a fabricação do produto: um copolímero acrílico fabricado pela BASF de nome comercial Luvset ${ }^{\circledR}$ 360, um espessante celulósico comercializado pela MC Química com nome HPMC kolagel ${ }^{\circledR}$ e o Aquawan 20, fornecido pela Wana Química (BASF, 2020; MC QUÍMICA, 2020; WANA QUÍMICA, 2020).

Outra matéria prima importante utilizada na produção de álcool em gel é o neutralizante que tem a função de regular o $\mathrm{pH}$ do produto, a escolha correta deste 
componente é crucial para obtenção de um gel transparente e espesso. O composto utilizado comumente na produção de álcool em gel é a trietanolamina (trieta), um composto orgânico que possui uma amina terciária ligada a cadeias alquílicas com grupo álcool. A dificuldade em trabalhar com este produto se deve à burocracia envolvida na sua aquisição e armazenamento, uma vez que este é controlado pela polícia federal. Para contornar esta problemática, decidiuse utilizar na produção o composto Etanolamina (2-aminoetanol), à custa de um sacrifício na viscosidade final do produto.

A água utilizada no processo produtivo era proveniente de um poço artesiano que abastece o reservatório do COT. Esta água em estado bruto não pode ser utilizada na produção do álcool em gel, pois seus sais e outros contaminantes podem afetar a qualidade e o tempo de vida útil do produto. Por este motivo, foram instalados destiladores de água a rede de alimentação da planta, estes destiladores produziam água purificada e, em seguida, era armazenada em containers IBC para ser utilizada posteriormente.

\subsection{Processo Produtivo}

O processo de produção do álcool em gel, cujo esquema simplificado é apresentado na Figura 1, consistia no bombeamento das matérias primas para um tanque de mistura construído em inox com capacidade de 2 mil litros com 2 metros de altura. Por conveniência eram produzidos mil litros de álcool em gel por batelada (por ciclo), o produto obtido era armazenado em um tanque de polipropileno de 5 mil litros, ao atingir a capacidade máxima deste tanque, uma amostra era enviada ao laboratório de controle de qualidade para atestar o teor de álcool, viscosidade e outros parâmetros. Com o produto dentro dos padrões exigidos, era liberado a quantia produzida para envase.

A equipe de produção era composta por cinco colaboradores, sendo um coordenador de produção e quatro auxiliares que trabalhavam no período matutino e vespertino. As atividades consistiam em determinar as quantias a serem bombeadas para o tanque de mistura, fazer o bombeamento destas quantidades e uma etapa de adição do neutralizante (Etanolamina) que era realizada manualmente através de uma porta de inspeção no topo do tanque de mistura. Não havia procedimentos padronizados para as atividades e os EPI's utilizados eram botas, máscara cirúrgica descartável e luvas e borracha.

Com o término do ciclo de produção e após a liberação do controle de qualidade o álcool em gel produzido era enviado ao setor de envase. A figura 2 mostra imagem da sala de envase. O setor de envase consistia em uma sala de $40 \mathrm{~m}^{2}$ climatizada, localizado um piso acima da área de produção. No seu interior havia tanques pulmão para o álcool em gel com capacidade para dois mil litros, conectado a máquinas de envase semiautomáticas com capacidade de produção de três mil frascos por hora. 
Pelufo, D.I.; Durante, L.C.; Diretrizes para implantação de um sistema de saúde e segurança do trabalho em empresas produtoras de álcool em gel. E\&S - Engineering and Science, 2021, 10.

Figura 1 - (a) Layout do processo produtivo e imagens (b) frontal da fábrica e (c) do estoque de álcool 96GL.

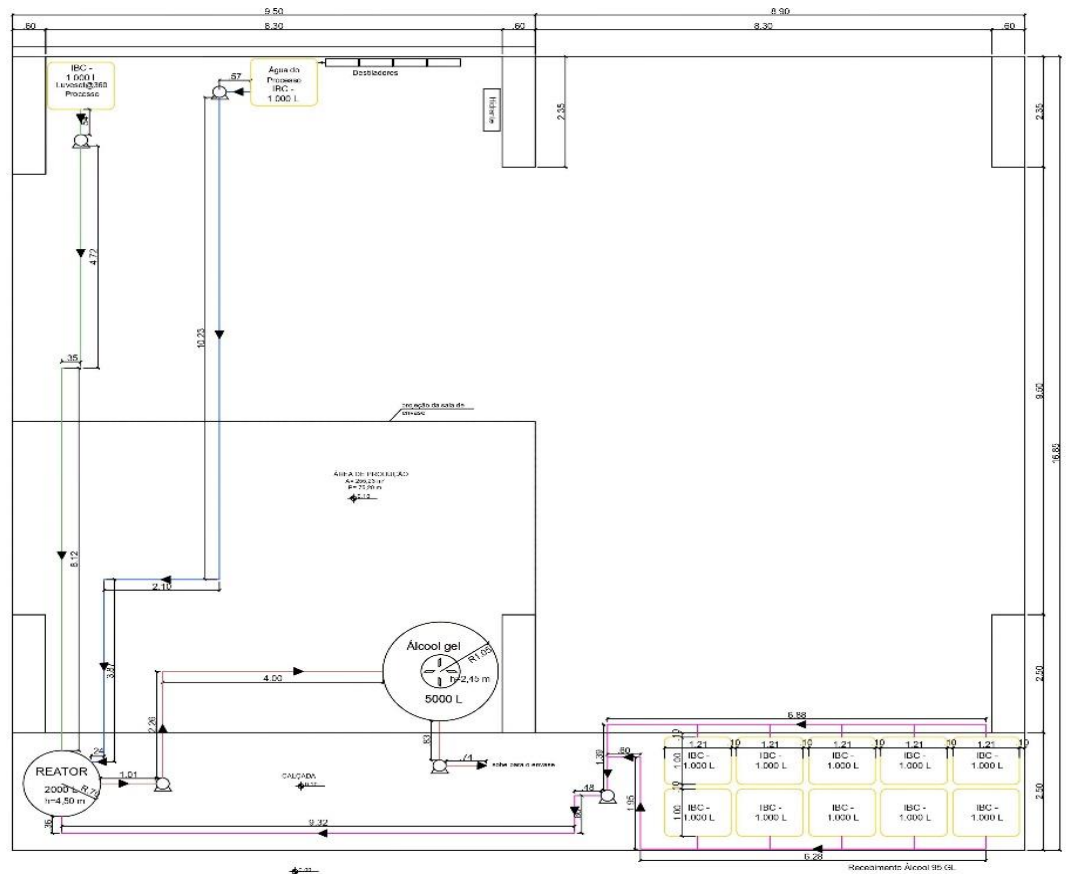

(a)

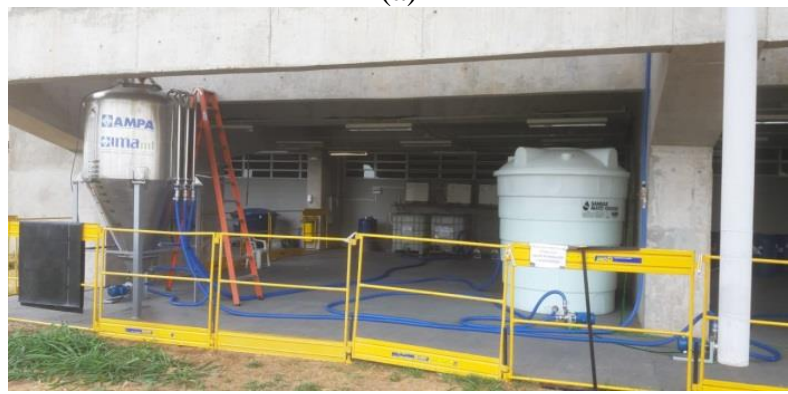

(b)

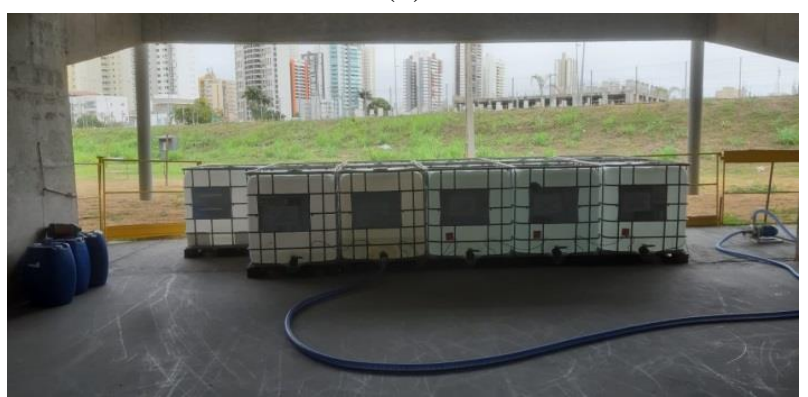

(c)

Figura 2 - Sala de envase do álcool em gel.

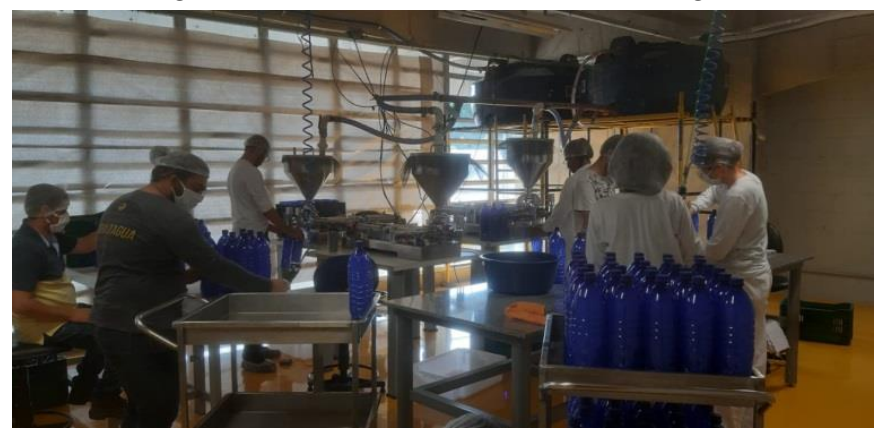




\section{RESULTADOS}

A fábrica produtora de álcool em gel, objeto desse estudo, surgiu de um projeto da Universidade Federal de Mato Grosso - UFMT, campus de Cuiabá, capital do estado de Mato Grosso. A planta de produção foi desenvolvida em caráter de urgência, contando com mais de 60 colaboradores e foi alocada no Centro Olímpico de Treinamento - COT da UFMT. A meta de produção de álcool em gel foi determinada em 65 mil litros que, posteriormente, foram destinados aos órgãos públicos e distribuídos para comunidade com intuito de proteger a população e facilitar o acesso ao produto.

A estrutura administrativa consistia em seis núcleos responsáveis pelos diferentes setores da fábrica (Figura 2).

Figura 2 - Estrutura organizacional da fábrica de produção de álcool em gel.

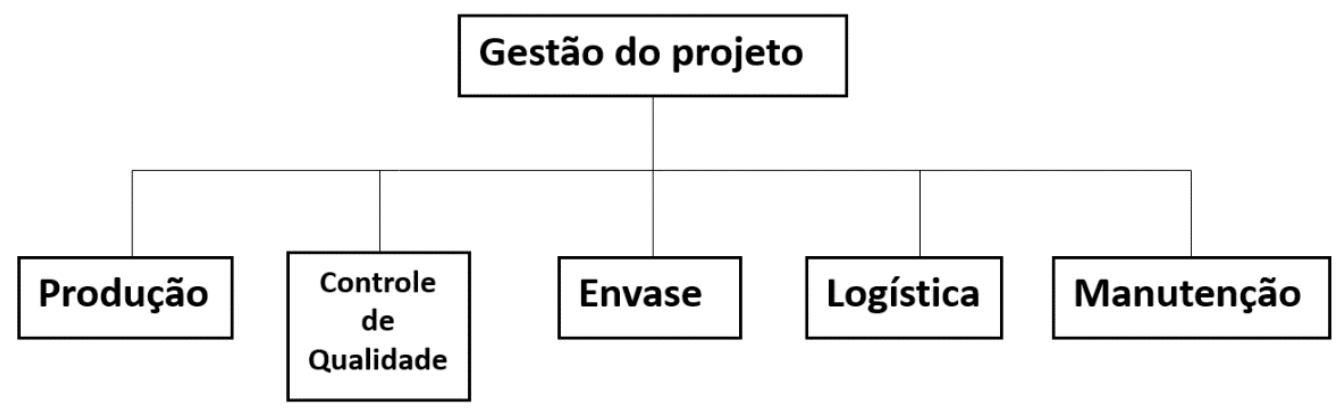

A gestão do projeto tinha responsabilidade de gerir as rotinas administrativas, controle de aquisição de matéria prima, controle de entrada e saída de materiais e outras atividades similares, além de garantir o funcionamento geral da fábrica.

O setor de produção era encarregado de produzir o álcool em gel, comunicar a demanda de matéria prima e fornecer a informação de quantidades produzidas. $\mathrm{O}$ controle de qualidade realizava as análises físico-químicas do produto para atestar a sua qualidade, além de fazer a sua liberação para as etapas seguintes.

O envase responsabilizava-se pela determinação dos volumes a serem envasados, em seguida, a expedição encarregava-se da contabilidade e controle de lotes dos frascos de produto, armazenamento e expedição e, por fim, o setor de manutenção era responsável pela limpeza e por fazer os reparos mecânicos à planta de produção.

Este trabalho teve maior foco sobre a área de produção, onde se procurou explorar o processo utilizado para produção de álcool. Os instrumentos de coleta de dados utilizados para sua realização foram: entrevistas realizadas a partir de questionamentos abertas dirigidas aos colaboradores, observação in loco e análise de documentos, principalmente as práticas de trabalho realizadas pela equipe de produção.

\subsection{Análise Preliminar de Risco}

A fim de tornar a APR com maior nível de detalhamento e com maior abrangência, optou-se por dividir as atividades produtivas em recebimento e armazenamento de álcool 96 GL, manuseio da matéria prima e preparo e armazenamento do produto acabado.

As atividades relacionadas ao recebimento de álcool 96 GL diz respeito a transferência do combustível do caminhão-tanque para os reservatórios (IBCs) da fábrica para serem utilizados na produção. A Tabela 5 apresenta os riscos envolvidos nesta atividade e os categoriza conforme o seu potencial de causar degradação, danos, perdas, mortes ou lesões. 
Pelufo, D.I.; Durante, L.C.; Diretrizes para implantação de um sistema de saúde e segurança do trabalho em empresas produtoras de álcool em gel. E\&S - Engineering and Science, 2021, 10.

Tabela 5 - Análise preliminar de risco das atividades de recebimento e armazenamento de álcool 96 GL.

\begin{tabular}{|c|c|c|c|c|c|}
\hline Atividade & Risco & Causa & Consequência & $\begin{array}{c}\text { Categoria } \\
\text { do risco }\end{array}$ & $\begin{array}{c}\text { Medidas } \\
\text { preventivas }\end{array}$ \\
\hline $\begin{array}{l}\text { Preparação do } \\
\text { Caminhão } \\
\text { tanque para } \\
\text { descarga do } \\
\text { álcool. }\end{array}$ & $\begin{array}{l}\text { Atropelamento } \\
\text { pelo } \\
\text { Caminhão- } \\
\text { tanque. }\end{array}$ & $\begin{array}{c}\text { Permanecer em } \\
\text { local } \\
\text { inapropriado } \\
\text { durante a } \\
\text { manobra do } \\
\text { caminhão-tanque. }\end{array}$ & $\begin{array}{l}\text { Danos pessoais, } \\
\text { escoriações, } \\
\text { fraturas, morte. }\end{array}$ & Moderado. & $\begin{array}{l}\text { Limitar a área ao } \\
\text { pessoal autorizado, } \\
\text { sinalizar o local, } \\
\text { delimitar a área de } \\
\text { descarga. }\end{array}$ \\
\hline $\begin{array}{l}\text { Descarga de } \\
\text { Combustível do } \\
\text { Caminhão } \\
\text { tanque - para } \\
\text { reservatórios. }\end{array}$ & $\begin{array}{l}\text { Liberação } \\
\text { acidental de } \\
\text { combustível. }\end{array}$ & $\begin{array}{l}\text { Transbordo } \\
\text { durante o } \\
\text { enchimento dos } \\
\text { IBCs. }\end{array}$ & $\begin{array}{l}\text { Contaminação } \\
\text { do solo. }\end{array}$ & Moderado. & $\begin{array}{l}\text { Inspeção dos IBCs } \\
\text { em busca de } \\
\text { vazamento, } \\
\text { coordenar equipe de } \\
\text { recebimento para } \\
\text { verificar nível dos } \\
\text { IBCs. }\end{array}$ \\
\hline $\begin{array}{c}\text { Descarga de } \\
\text { Combustível do } \\
\text { Caminhão } \\
\text { tanque para os } \\
\text { IBCs. }\end{array}$ & $\begin{array}{l}\text { Incêndio } \\
\text { Explosão. }\end{array}$ & $\begin{array}{l}\text { Ignição } \\
\text { eletrostática e } \\
\text { mistura de ar e } \\
\text { combustível. }\end{array}$ & $\begin{array}{c}\text { Danos materiais } \\
\text { e pessoais } \\
\text { graves. }\end{array}$ & $\begin{array}{c}\text { Não } \\
\text { Tolerável. }\end{array}$ & $\begin{array}{c}\text { Verificar a } \\
\text { existência de } \\
\text { extintores, realizar o } \\
\text { aterramento do } \\
\text { caminhão e dos } \\
\text { IBCs. }\end{array}$ \\
\hline $\begin{array}{c}\text { Armazenamento } \\
\text { do álcool } 96 \mathrm{GL} \\
\text { para produção. }\end{array}$ & $\begin{array}{l}\text { Incêndio } \\
\text { Explosão. }\end{array}$ & $\begin{array}{l}\text { Ignição } \\
\text { eletrostática e } \\
\text { mistura de ar e } \\
\text { combustível. }\end{array}$ & $\begin{array}{c}\text { Danos materiais } \\
\text { e pessoais } \\
\text { graves. }\end{array}$ & $\begin{array}{c}\text { Não } \\
\text { Tolerável. }\end{array}$ & $\begin{array}{l}\text { Verificar existência } \\
\text { de extintores, em } \\
\text { local ventilado, } \\
\text { realizar o } \\
\text { aterramento, } \\
\text { sinalizar e limitar o } \\
\text { acesso. } \\
\end{array}$ \\
\hline
\end{tabular}

As atividades relacionadas ao recebimento e armazenamento do álcool combustível 96 GL são categorizadas como não toleráveis quanto ao seu grau de risco. Usualmente, em postos de combustíveis, por exemplo, estas atividades são interpretadas como sendo de risco moderado, pois os reservatórios e equipamentos utilizados são projetados especificamente para estas atividades. A fábrica necessita de um cuidado especial com relação ao armazenamento do álcool $96 \mathrm{GL}$, uma vez que os tanques utilizados por ela não são específicos para combustíveis e, apesar de poderem ser utilizados para este fim, não possuem sistema de aterramento para evitar centelhas provenientes de eletricidade estática.

A Tabela 6 apresenta as atividades de manuseio da matéria prima e produção do álcool em gel 70\% INPM. Nestas atividades há riscos químicos, de lesões e falha de equipamentos, visto que o polímero utilizado como espessante na produção de álcool em gel que chegavam na fábrica em bombonas plástica de tampa fixa com volume de 200 litros e precisavam ser bombeadas para um reservatório (IBC) ligado ao tanque de produção do álcool em gel. 
Pelufo, D.I.; Durante, L.C.; Diretrizes para implantação de um sistema de saúde e segurança do trabalho em empresas produtoras de álcool em gel. E\&S - Engineering and Science, 2021, 10.

Tabela 6 - Análise preliminar de risco das atividades de manuseio de matéria prima e produção do álcool em gel 70\% INPM e Armazenamento do produto acabado.

\begin{tabular}{|c|c|c|c|c|c|}
\hline Atividade & Risco & Causa & Consequência & $\begin{array}{c}\text { Categoria } \\
\text { do risco }\end{array}$ & $\begin{array}{c}\text { Medidas } \\
\text { preventivas }\end{array}$ \\
\hline $\begin{array}{l}\text { Bombeamento do } \\
\text { polímero. }\end{array}$ & $\begin{array}{c}\text { Vazamento de } \\
\text { polímero durante a } \\
\text { transferência para } \\
\text { o tanque } \\
\text { reservatório (IBC). } \\
\text { Quando pó } \\
\text { formação de } \\
\text { nevoas. }\end{array}$ & $\begin{array}{l}\text { Transbordo } \\
\text { durante o } \\
\text { manuseio das } \\
\text { bombonas; } \\
\text { vazamento na } \\
\text { bomba e } \\
\text { geração de } \\
\text { poeira ao } \\
\text { manusear. }\end{array}$ & $\begin{array}{c}\text { Reações adversas } \\
\text { em contato com a } \\
\text { pele dos } \\
\text { colaboradores. } \\
\text { Quando pó } \\
\text { irritações do } \\
\text { sistema } \\
\text { respiratório ou } \\
\text { dos olhos. }\end{array}$ & Moderado. & $\begin{array}{c}\text { Uso de EPI, } \\
\text { inspeção prévia } \\
\text { das bombas, } \\
\text { válvulas e } \\
\text { tubulações, adotar } \\
\text { procedimento } \\
\text { padrão para a } \\
\text { operação. }\end{array}$ \\
\hline $\begin{array}{l}\text { Bombeamento do } \\
\text { álcool } 96 \text { GL para } \\
\text { o tanque de } \\
\text { produção. }\end{array}$ & $\begin{array}{l}\text { Liberação } \\
\text { acidental de } \\
\text { álcool. }\end{array}$ & $\begin{array}{c}\text { Ruptura ou } \\
\text { vazamento } \\
\text { em conexões, } \\
\text { válvulas e } \\
\text { tubulações. }\end{array}$ & $\begin{array}{l}\text { Exposição dos } \\
\text { colaboradores aos } \\
\text { vapores de } \\
\text { combustível, } \\
\text { contaminação do } \\
\text { solo. }\end{array}$ & Tolerável. & $\begin{array}{c}\text { Elaborar um plano } \\
\text { de manutenção, } \\
\text { manter } \\
\text { mangueiras } \\
\text { estendidas para } \\
\text { evitar } \\
\text { dobramentos, } \\
\text { fazer a elevação } \\
\text { dos IBCs para } \\
\text { coletar o álcool } \\
\text { liberado na troca } \\
\text { de conexões. } \\
\end{array}$ \\
\hline $\begin{array}{l}\text { Bombeamento do } \\
\text { álcool } 96 \text { GL para } \\
\text { o tanque de } \\
\text { produção. }\end{array}$ & $\begin{array}{l}\text { Incêndio } \\
\text { Explosão. }\end{array}$ & $\begin{array}{l}\text { Contato do } \\
\text { combustível } \\
\text { com parte } \\
\text { elétrica da } \\
\text { bomba. } \\
\text { Eletricidade } \\
\text { Estática. }\end{array}$ & $\begin{array}{l}\text { Danos materiais e } \\
\text { pessoais graves. }\end{array}$ & $\begin{array}{c}\text { Não } \\
\text { Tolerável. }\end{array}$ & $\begin{array}{c}\text { Aterramento das } \\
\text { bombas, utilização } \\
\text { de bombas } \\
\text { pneumáticas. }\end{array}$ \\
\hline $\begin{array}{l}\text { Dosagem de } \\
\text { trietanolamina ou } \\
\text { monoetanolamina. }\end{array}$ & Queda/altura & $\begin{array}{l}\text { Atividade } \\
\text { realizada a } 2 \\
\text { metros do } \\
\text { solo. }\end{array}$ & $\begin{array}{l}\text { Danos pessoais, } \\
\text { lesões, fraturas. }\end{array}$ & Moderado & $\begin{array}{c}\text { Uso de EPI, } \\
\text { elaboração de } \\
\text { procedimento de } \\
\text { dosagem, adotar o } \\
\text { uso de bombas } \\
\text { dosadoras. }\end{array}$ \\
\hline $\begin{array}{l}\text { Dosagem de } \\
\text { trietanolamina ou } \\
\text { monoetanolamina. }\end{array}$ & $\begin{array}{l}\text { Queimadura } \\
\text { química }\end{array}$ & $\begin{array}{l}\text { Transbordo } \\
\text { durante o } \\
\text { manuseio do } \\
\text { produto. }\end{array}$ & $\begin{array}{l}\text { Danos pessoais, } \\
\text { lesões. }\end{array}$ & $\begin{array}{c}\text { Não } \\
\text { Tolerável }\end{array}$ & Idem anterior \\
\hline $\begin{array}{l}\text { Amostragem de } \\
\text { álcool gel } 70 \% \text {. }\end{array}$ & Queda/altura & $\begin{array}{c}\text { Atividade } \\
\text { realizada a } \\
2 \mathrm{~m} \text { de altura. }\end{array}$ & $\begin{array}{l}\text { Danos pessoais, } \\
\text { lesões, fraturas. }\end{array}$ & Moderado & Idem anterior. \\
\hline $\begin{array}{l}\text { Bombeamento de } \\
\text { álcool em gel para } \\
\text { o tanque de } \\
\text { estocagem. }\end{array}$ & $\begin{array}{l}\text { Incêndio,Explosão, } \\
\text { curto circuito }\end{array}$ & $\begin{array}{l}\text { Contato do } \\
\text { álcool em gel } \\
\text { com parte } \\
\text { elétrica da } \\
\text { bomba. } \\
\text { Eletricidade } \\
\text { Estática. } \\
\end{array}$ & $\begin{array}{l}\text { Danos materiais e } \\
\text { pessoais graves. }\end{array}$ & $\begin{array}{l}\text { Não } \\
\text { Tolerável }\end{array}$ & $\begin{array}{c}\text { Aterramento das } \\
\text { bombas, utilização } \\
\text { de bombas } \\
\text { pneumáticas. }\end{array}$ \\
\hline
\end{tabular}


Conforme observado na tabela 3 a maior preocupação no processo de produção álcool em gel está ligado ao manuseio do álcool 96 GL e ao produto acabado, devido, principalmente, ao risco de incêndio e explosões.

Baseado na APR, nos dados obtidos da observação da fábrica e no referencial teórico, foi possível elaborar diretrizes gerais para contribuir com a implementação de um sistema de saúde e segurança do trabalho e, também, contribuir com as principais preocupações acerca da elaboração de uma linha de produção de álcool em gel.

\subsection{Diretrizes para o Processo Produtivo de Fabricação de Álcool em Gel 70\%}

O primeiro aspecto fundamental na implantação de um sistema de saúde e segurança do trabalho está relacionado à inciativa dos diretores da organização. A alta administração deve ter papel efetivo em todas as etapas de implantação, no planejamento, na execução e na avaliação contínua dos resultados alcançados, além disto, a alta direção tem como responsabilidade prover os recursos necessários como infraestrutura, capacitação do pessoal e fornece um ambiente de trabalho adequado para todos na empresa. Este comprometimento é fundamental e demonstra que a saúde e segurança no trabalho é um valor chave para a organização e não apenas uma necessidade eventual (OLIVEIRA et al., 2010; VITORELI E CARPINETTI, 2013).

A saúde e segurança no trabalho deve ser vista pelos colaboradores como essencial e deve fazer parte das crenças e valores de todos. Quando este aspecto faz parte da cultura da organização, as atitudes e comportamento do pessoal com relação a saúde e segurança se desenvolve e persiste. Por este motivo é fundamental realizar uma prévia análise do perfil dos colaboradores para verificar o grau de escolaridade, capacitação profissional, a participação e o relacionamento com lideranças e colegas de trabalho a fim de prevenir e identificar resistência ao processo de implantação do sistema de saúde e segurança no trabalho (GONÇALVES FILHO E ANDRADE, 2012).

A implantação de um sistema de saúde e segurança no trabalho envolve a mudança de rotinas e modo de encarar as atividades cotidianas de uma organização, por isto, esta mudança, muitas vezes é enfrentada com resistência, devido, principalmente, pelo medo ao desconhecido, falta de informação, dúvidas sensação de perda de autoridade. Estas resistências podem ser atenuadas ou até mesmo contornadas por meio de incentivos à participação no processo de implantação, consideração e valorização de opiniões, disponibilização de informações e acesso à capacitação (PASQUINI, 2014).

Uma vez que o processo de implantação depende do envolvimento de todos na organização, a capacitação dos profissionais que exercem cargo de direção, gerência e supervisão e, inclusive, os colaboradores das áreas operacionais é fundamental. Por motivos similares à necessidade de capacitação, parceria com o setor de recursos humanos (RH), visto que este possui uma visão geral do quadro de funcionários, por isto, tem maior capacidade de identificar os riscos de cada função exercida na organização. Esta característica é importante, uma vez que facilita o reconhecimento dos treinamentos necessários para o desenvolvimento dos colaboradores das áreas técnicas e pessoal relacionado à área organizacional (OLIVEIRA et al., 2010).

A adoção de sistemas de acompanhamento do desempenho do sistema de gerenciamento em saúde e segurança no trabalho, como por exemplo, o uso de indicadores é de grande importância, pois podem ser utilizados como uma ferramenta gerencial, criando oportunidades de identificar oportunidades de melhorias. O monitoramento do sistema de saúde e segurança no trabalho produz uma vantagem estratégica para a organização, uma vez que reduz acidentes e afastamentos do trabalho, colabora com o aumento da produção, reduzindo os custos dentro da organização (ALMEIDA E ARAÚJO NUNES, 2014). 
Conforme demonstrado pela análise preliminar de risco a principal preocupação no processo produtivo está relacionado à manipulação de álcool 96 GL e dos reagentes, por este motivo é importante considerar estes riscos durante a idealização do processo de produção de modo que durante a operação da planta de produção estes riscos sejam minimizados ou, até mesmo, eliminados.

Com relação ao estoque de álcool 96 GL a organização deve levar em consideração a Norma Regulamentadora da Secretaria Especial de Previdência e Trabalho do Ministérios da economia NR 20 - Segurança e Saúde no Trabalho com Inflamáveis e Combustíveis (BRASIL, 2019), norma regulamentadora que trata sobre a execução de trabalhos com inflamáveis e combustíveis, além das normas do corpo de bombeiros.

Deste modo, deve ser observada a quantidade mínima de álcool a ser estocada para a produção. Pois, entende-se que o álcool etílico é uma substância considerada inflamável, visto que seu ponto de fulgor é por volta de $13^{\circ} \mathrm{C}$ e seu armazenamento em grande quantidade deve ser planejado de modo a cumprir as determinações das normas citadas.

Na fábrica, a quantidade armazenada para a produção era de 10 mil litros, esta quantia de armazenamento põe a fábrica no limite para ser considerada como de classe I de acordo com a NR 20 (BRASIL, 2019). No entanto, mesmo não sendo enquadrada como de classe I é importante observar a necessidade de organizar treinamentos periódicos para capacitação do pessoal que lidam diretamente no manuseio do álcool.

Como medida coletiva de prevenção de acidentes é importante escolher o local de armazenamento longe de fontes de calor e ignição, posicionando-o em local fresco de baixa temperatura e bem ventilado, visto que o álcool entra em autoignição a $380^{\circ} \mathrm{C}$. $\mathrm{O}$ uso de meios de contenção para o caso de pequenos derramamentos ou vazamentos acidentais deve ser considerado para evitar contato do álcool com o solo e corpos d'água, além de evitar acidentes mais graves.

Para mais, um plano de prevenção e controle de vazamentos, derramamentos, incêndio e explosões deve ser elaborado. Este plano tem por finalidade estabelecer procedimentos técnicos e administrativos, a serem adotados em situações emergenciais que eventualmente possam ocorrer no chão de fábrica. O plano deverá abordar critérios de controle para minimizar as consequências de um eventual acidente, abordando temas de segurança, controle de vazamento e aspectos ambientais. É de vital importância que a organização seja responsável por informar, esclarecer, reforçar os procedimentos para todos os colaboradores, quanto aos procedimentos corretos a serem tomados em casos de emergências.

A eletricidade estática também deve ser considerada ao planejar o armazenamento, uma vez que as matérias podem acumular cargas que são suficientes para iniciar um incêndio ou explosão, portanto, o aterramento dos tanques e bombas são medidas essenciais para evitar este tipo de acidentes, principalmente, na operação de descarga do caminhão-tanque.

$\mathrm{Na}$ fábrica, o armazenamento do álcool da produção era feito em IBCs de mil litros, por este motivo, havia conexões destacáveis às válvulas destes tanques que eram utilizadas para conectá-los ao sistema de bombeamento. Quando um IBCs era esvaziado, o colaborador fazia troca das conexões para um IBC cheio, de modo a continuar o processo de produção. Frequentemente, nestas trocas havia derramamento de álcool. Devido a este tipo de situação é necessário considerar o uso de conexões e válvulas que conecte todos os IBCs em um só sistema de tubulações ou optar por um tanque único para o armazenamento do líquido inflamável, sempre observando o disposto na NR 20 (BRASIL, 2019).

O sistema de extintores deve ser previsto no projeto de combate a incêndios da instalação, no entanto, é importante entender as regras utilizadas pelo corpo de bombeiros referente à armazenamento de líquidos inflamáveis, uma vez que a organização deverá ter pessoal capacitado para operar o sistema de extintores. De acordo com a Técnica do Corpo de Bombeiros do estado de Mato Grosso NTCB n²4/2019 (CBMMT, 2020), deve ser 
considerada a capacidade de cada tanque, quando for isolado ou a somatória da capacidade dos tanques individuais.

Para o caso em estudo, como o total armazenado é de 10 mil litros, a capacidade extintora mínima deve ser de dois extintores de pó 80-B e dois extintores de espuma mecânica 10-B ou um extintor de pó 40-B, um extintor sobre rodas de pó $80 \mathrm{~B}$, dois extintores de espuma mecânica 10-B.

As medidas individuais de prevenção são planejadas de modo a evitar o contato do colaborador com o líquido inflamável ou seus vapores, por isto são considerados nessa situação equipamentos de proteção respiratória com filtro contra vapores e névoas, luvas de proteção de PVC, borracha nitrílica ou natural e óculos de proteção contra respingos.

Procedimentos operacionais das atividades e um plano de manutenção que contemple os equipamentos, máquinas, tubulações e acessórios, instrumentos, tipos de intervenções, quando houver, procedimentos de inspeção e manutenção. Este plano deve ser periodicamente revisado e atualizado, considerando o previsto nas normas regulamentadoras e técnicas disponíveis.

\section{Gel $70 \%$}

3.3. Diretrizes para o Manuseio das Matérias Primas da Produção de Álcool em

É importante que a organização que lida com as matérias primas da produção de álcool em gel mantenha disponível as fichas de informações de segurança para produtos químicos, FISPQ ou, em inglês, MSDS - Material Safety Data Sheet. Estas devem ser elaboradas conforme a Norma Técnica NBR 14.725 Produtos químicos - Informações sobre segurança, saúde e meio ambiente Parte 2: Sistema de classificação de perigo (ABNT, 2019). As informações contidas nas FISPQs podem e devem ser utilizadas durante a concepção do sistema de saúde e segurança no trabalho e na elaboração do processo produtivo, através delas é possível determinar as medidas coletivas e individuais de proteção e, além disto, podem ser utilizadas para determinar os procedimentos de manuseio dos produtos químicos, assim como os equipamentos do processo de produção.

O álcool em gel pode ser obtido por diferentes matérias primas, no entanto, os carbômeros são os agentes gelificantes/ espessantes tradicionalmente utilizados na fabricação deste produto. O mais conhecido dentre os carbômeros é o Carbopol 940 que possui $n^{\circ}$ CAS (registro único no banco de dados do Chemical Abstracts Service) 7446-81-6 e, segundo o Sistema Globalmente Harmonizado de Classificação e Rotulagem de Produtos Químicos, referido pela sigla GHS (do inglês Globally Harmonized System of Classification and Labeling of Chemicals) esta substância é tóxica para vida aquática, portanto, deve haver precauções e cuidados em sua manipulação e descarte. Além disto, por ser um pó, pode causar irritação aos olhos, pele e sistema respiratório (PUBCHEM, 2021a).

As medidas proteção coletivas devem considerar adaptar o processo produtivo de forma a evitar que os colaboradores tenham contato com o pó, uma alternativa viável, dependendo do volume de produção, é o uso de transporte pneumático, ou seja, o pó que deve ser alimentado ao tanque de mistura para produzir o álcool em gel, é levado por linhas pneumáticas, isso pode diminuir ou até evitar o contato dos colaboradores com o produto. No entanto, é necessário observar que este tipo de abordagem diminui a flexibilidade do sistema de produção, uma vez que o sistema pneumático só trabalha com pós e inviabiliza a utilização de matérias primas na forma liquida.

Foi observado que a fábrica utilizou matérias primas na forma de pó e líquido. O pó utilizado é um espessante baseado em celulose, usualmente, a carboximetilcelulose (CMC) que possui $n^{\circ}$ CAS 9000-11- 7, e não possui classificação na GHS e de acordo com a agencia americana de proteção ambiental, referida pela sigla EPA (U.S. Environmental Protection Agency) a CMC não oferece preocupação. No entanto por se tratar de um pó, as mesmas 
medidas adotadas para o Carbopol 940 são validas. Já as matérias primas na forma líquida, que foram duas, são baseadas em uma dispersão aquosa de copolímero acrílico que tem a mesma natureza química do Carbopol 940, porém, neste caso, o polímero está suspenso em um líquido, mesmo assim, pode causar irritações quando em contato com olhos e pele (PUBCHEM, 2020b,2021c).

Os polímeros na forma líquida eram recebidos pela fábrica em bombonas de 200 litros, em seguida, eram transferidos para um IBC por meio de uma bomba periférica, por vezes era observado derramamentos que, consequentemente, faziam com que o produto entrasse em contato com o colaborador que executava a operação. Luvas de PVC, camisa, calça, galocha de borracha e óculos de proteção eram os EPIs utilizados por ele.

O principal neutralizante utilizado no processe de fabricação de álcool gel é a trietanolamina CAS 102-71-6, um líquido amarelo pálido que deve ser utilizado com muita cutela, pois é uma substância perigosa, apresentando risco intoxicação aguda, irritação e até queimadura da pele, pode causar danos aos olhos e, ainda, danos a órgãos por exposição prolongada ou repetida (PUBCHEM, 2021d).

No processo produtivo a adição desta substância era feita em pequenas quantidades, para cada 1000 litros de álcool em gel produzido, cerca de 3 litros eram utilizados. A adição era feita de forma manual diretamente pela porta de inspeção do tanque de mistura, o pessoal que desempenhava a atividade utilizava máscaras com filtro contra vapor, luvas de PVC e óculos de proteção.

Uma alternativa que pode ser adotada como medida de proteção coletiva é a utilização de bombas de dosagem ou peristálticas, arranjadas de forma a se adaptar à embalagem da Trieta, evitando que haja contato direto com a substância. A quantidade utilizada pode ser controlada pela medida do $\mathrm{pH}$ e da viscosidade do produto.

Outros neutralizantes podem ser empregados no processo de fabricação de álcool em gel, a etanolamina CAS 141-43-5 e hidróxido de sódio CAS 1310-73-2 são dois exemplos populares entre os fabricantes do gel, apesar de o produto obtido com estas substâncias apresentar menor viscosidade e maior turbidez, a preferência por eles está associada ao menor custo. A etanolamina pode causar toxidade aguda, queimadura da pele e olhos, além de ser nocivo se inalado. Similarmente, o hidróxido de sódio pode causar severas queimaduras na pele, já que é uma substância extremamente corrosiva (PUBCHEM, 2021e; 2021f).

A mesma estratégia utilizada para Trieta pode ser adotada para a etanolamina e o hidróxido de sódio, é importante observar que os neutralizantes citados não são utilizados concentrados, é necessário o preparo de soluções conforme especificado em formulação. Estas soluções devem ser feitas em capela com fluxo de exaustão e o profissional que desenvolve o procedimento deve estar devidamente utilizando os EPIs adequados.

\section{CONSIDERAÇÕES FINAIS}

O aumento da demanda por higienizastes e sanitizantes, ocasionou um surgimento crescente fabricantes de álcool em gel. Dentro deste contexto, um sistema de saúde e segurança do trabalho pode trazer inúmeros benefícios a estas empresas, uma vez que possibilita a construção de um processo mais eficiente e seguro.

Sua implementação, no entanto, pode enfrentar dificuldades, diante da imensidade de informações necessárias de diferentes áreas do conhecimento, baixo engajamento por parte da administração e funcionários.

Este estudo trouxe uma avaliação detalhada do processo produtivo de álcool em gel que teve intuito de desenvolver diretrizes para auxiliar nas atividades operacionais e na concepção do processo produtivo. 
Através da APR foi observado que as atividades relacionadas ao armazenamento de álcool 96 GL tem alto impacto para segurança das operações e, por isto, estas atividades devem ser idealizadas com cuidado observando a legislação desde as etapas de concepção até as operações do dia a dia.

APR também demonstrou que o levantamento das informações dos agentes químicos utilizados na fabricação do álcool em gel é fundamental para definir a forma correta em que o processo é executado, além disto, auxilia na escolha dos EPIs e Equipamentos de proteção coletiva (EPCs), visto que alguns compostos são extremamente perigosos.

As diretrizes trouxeram orientações quanto à postura dos funcionários e alta administração para a construção de uma cultura de segurança do trabalho. Também orientou sobre alternativas de equipamentos de processo e sua importância na produção, além disto, também foi demonstrada a importância de se considerar a legislação brasileira quando se manipula líquidos inflamáveis.

A pesquisa das informações a respeito das substâncias químicas e suas características individuais conduzem a orientações importantes que direcionam a organização da produção e as formas corretas de operar o processo e manipular cada agente químico.

De forma geral, o estudo realizado na fábrica de produção de álcool em gel contribuiu para esclarecer questões importantes relacionadas à saúde e segurança no trabalho, fornecendo orientações importantes que podem contribuir para construção de processos produtivos mais eficientes e seguros.

\section{REFERÊNCIAS}

ALMEIDA, Clarissa Lima; DE ARAÚJO NUNES, Ana Bárbara. Proposta de indicadores para avaliação de desempenho dos sistemas de gestão ambiental e de segurança e saúde no trabalho de empresas do ramo de engenharia consultiva. Gestão e Produção, v. 21, n. 4, p. 810-820, 2014. https://doi.org/10.1590/0104-530X649.

ANVISA. Formulário Nacional da Farmacopeia Brasileira 2a edição - Revisão 02. 2012. Disponível em: http://antigo.anvisa.gov.br/formulario-nacional. Acesso em: 28 set. 2020.

ASSOCIAÇÃO BRASILEIRA DE NORMAS E TÉCNICAS. NBR 14725: Produtos químicos - Informações sobre segurança, saúde e meio ambiente parte 2: Sistemas de calssificação de perigo. Rio de janeiro, 2009.

ATKINS, Peter; JONES, Loretta. Princípios de Química Questionando a vida moderna e o meio ambiente. 5. ed. Porto Alegre: Bookman, 2012. 848p.

BASF. LUVISET ${ }^{\circledR} \quad 360 . \quad$ BASF. 2020. Disponível em: https://www.shop.basf.com.br/homecare/pt/BRL/brands/PRODUTOS/LUVISET®-360/p/30765065. Acesso em: 2 out. 2020.

BASILIO, João Carlos. Faturamento com álcool gel deve ser dez vezes maior que em 2019. 2020. Disponível em: https://abihpec.org.br/45216-2/. Acesso em: 28 set. 2020.

BOYCE, John M. Using Alcohol for Hand Antisepsis: Dispelling Old Myths. Infection Control \& Hospital Epidemiology, v. 21, n. 7, p. 438-441, 2000. https://doi.org/10.1086/501784

BRASIL. Ministério da Saúde. RESOLUÇÃO - RDC No 350, DE 19 DE MARÇO DE 2020.Brasília, 2020. Disponível em: https://www.in.gov.br/en/web/dou/-/resolucao-rdc-n350-de-19-de-marco-de-2020-249028045. Acesso em: 28 set. 2020. 
BRASIL. Secretaria Especial de Previdência e Trabalho. NR 20 - Segurança e Saúde no trabalho com inflamáveis e Combustíveis. Ministério da Economia, Brasília, 2019. 24p. Disponível em: https://enit.trabalho.gov.br/portal/images/Arquivos_SST/SST_NR/NR-20atualizada-2019.pdf. Acesso em: 28 jan. 2021

CBMMT. CORPO DE BOMBEIROS MILITAR DO ESTADO DE MATO GROSSO. NTCB $\mathrm{n}^{\circ} 24$ - Armazenamento de líquidos inflamáveis e combustíveis, Cuiabá, 2020. 65p. Disponível em: http://www.cbm.mt.gov.br/servico.php?id=431. Acesso em: 19 nov. 2020.

CORRÊIA, Douglas. Ambev doará 500 mil garrafas de álcool gel a hospitais públicos. 2020. Disponível em: https://agenciabrasil.ebc.com.br/geral/noticia/2020-03/ambev-vai-doar500-mil-garrafas-de-alcool-em-gel-hospitais-publicos. Acesso em: 2 out. 2020.

EVERETT, D. H., . Manual of Symbols and Terminology for Physicochemical Quantities and Units, Appendix II: Definitions, Terminology and Symbols in Colloid and Surface Chemistry. Pure Appl. Chem, v. 31, n. July, p. 577-638, 2009.

FOLHA DE PERNANBUCO. Cervejarias artesanais produzem álcool para combate ao coronavírus. 2020. Disponível em: https://www.folhape.com.br/economia/cervejariasartesanais-produzem-alcool-para-combate-ao-coronavirus/137079/. Acesso em: 2 out. 2020.

GONÇALVES FILHO, Anastácio Pinto; ANDRADE, José Célio Silveira; MARINHO, Marcia Mara de Oliveira. Modelo para a gestão da cultura de segurança do trabalho em organizações industriais. Production, v. 23, n. 1, p. 178-188, 2012. http://dx.doi.org/10.1590/S0103-65132012005000044.

JENKINS, Scott. Information on hazards of manufacturing hand sanitizer offered by DEKRA N.A. 2020. Disponível em: https://www.chemengonline.com/information-onhazards-of-manufacturing-hand-sanitizer-offered-by-dekra-n-a/. Acesso em: 2 out. 2020.

MAGALHÃES, Wallace C. Porto. Alternativas para Fabricação de Álcool em Gel. 2020. Disponível em: https://cosmetoguia.com.br/article/read/area/IND/id/273/. Acesso em: 28 set. 2020.

MAGALHÃES, Washington Luiz Esteves; DEGENHARDT, Juliana. Nova formulação de álcool gel (MicroCelol) com celulose microfibrilada (MFC): avaliação em Escherichia coli. Embrapa Florestas - Comunicado Técnico, v. 444, p. 9, 2020.

MC QUÍMICA. Kolagel ®. MC QUÍMICA 2020. Disponível em: https://mcquimica.com.br/personalcare/. Acesso em: 19 jan. 2021.

OLIVEIRA, Otávio José de; OLIVEIRA, Alessandra Bizan de; ALMEIDA, Renan Augusto de. Guidelines to implement occupational health and safety systems in automotive batteries manufacturers. Gestão e Produção, v. 17, n. 2, p. 407-419, 2010. https://doi.org/10.1590/S0104-530X2010000200014.

PETROBRAS. N-2782 Técnicas Aplicáveis à Análise de Riscos Industriais N-2782., 2015.

PUBCHEM. Sodium acrylate C3H3NaO2. 2021a. Disponível em: https://pubchem.ncbi.nlm.nih.gov/compound/4068533\#section=Identification. Acesso em: 18 jan. 2021.

PUBCHEM. Carmellose sodium C8H15NaO8. 2021b. Disponível em: https://pubchem.ncbi.nlm.nih.gov/compound/23706213\#section=Hazards-Identification. 
Pelufo, D.I.; Durante, L.C.; Diretrizes para implantação de um sistema de saúde e segurança do trabalho em empresas produtoras de álcool em gel. E\&S - Engineering and Science, 2021, 10.

Acesso em: 18 jan. 2021.

PUBCHEM. Acrylic acid CH2=CHCOOH. 2021c. Disponível em: https://pubchem.ncbi.nlm.nih.gov/compound/6581\#section=Toxicity. Acesso em: 19 jan. 2021.

PUBCHEM. Triethanolamine C6H15NO3. 2021d. Disponível em: https://pubchem.ncbi.nlm.nih.gov/compound/7618\#section=Health-Hazards. Acesso em: 19 jan. 2021.

PUBCHEM. Sodium Hydroxide NaOH. 2021e. Disponível em: https://pubchem.ncbi.nlm.nih.gov/compound/14798\#section=Safety-and-Hazards. Acesso em: 19 jan. 2021.

PUBCHEM. Ethanolamine C2H7NO. 2021f. Disponível em: https://pubchem.ncbi.nlm.nih.gov/compound/700\#section=GHS-Classification. Acesso em: 19 jan. 2021.

SEQUINEL, Rodrigo; LENZ, Guilherme; SILVA, Francis; SILVA, Fabiano. Soluções a base de álcool para higienização das mãos e superfícies na prevenção da covid-19: compêndio informativo sob o ponto de vista da química envolvida. Química Nova, , v. 43, n. 5, p. 679-684, 2020. http://dx.doi.org/10.21577/0100-4042.20170553.

TAVARES, José da Cunha. Noções de Prevenção e Controle de Perdas em Segurança do Trabalho. 9. ed. São Paulo. 176p.

THOMSON, Euan L.; BULLIED, Andrew R. Production of Ethanol-Based Hand Sanitizer in Breweries During the COVID-19 Crisis. Technical Quarterly, v. 57, n. 1, p. 47-52, 2020. https://doi.org/10.1094/TQ-57-1-0417-01

TODD, Ewen C. D.; MICHAELS, Barry S.; HOLAH, John; SMITH, Debra; GREIG, Judy D.; BARTLESON, Charles A. Outbreaks where food workers have been implicated in the spread of foodborne disease. Part 10. Alcohol-based antiseptics for hand disinfection and a comparison of their effectiveness with soaps. Journal of Food Protection, v. 73, n. 11, p. 2128-2140, 2010. https://doi.org/10.4315/0362-028X-73.11.2128.

TOLEDO, Penélope. Informações sobre o uso de álcool em gel. 2020. Instituto Nacional de Controle de Qualidade em Saúde. Disponível em: https://www.incqs.fiocruz.br/index.php?option=com_content\&view=article\&id=2219:atencao -informacoes-sobre-o-uso-de-alcool-em-gel\&catid=42\&Itemid=132. Acesso em: 13 out 2020

VITORELI, Gislaine Aparecida; CARPINETTI, Luiz Cesar Ribeiro. Analysis of the integration of normalized management systems ISO 9001 and OHSAS 18001: Multiple case studies. Gestão \& Produção, v. 20, n. 1, p. 204-217, 2013. https://doi.org/10.1590/S0104-530X2013000100015.

WANA QUÍMICA. Linha AQUAWAN. WANA QUÍMICA. 2020. Disponível em: https://wanaquimica.com.br/linha-aquawan/. Acesso em: 19 jan. 2021.

YIN, R. K. Estudo de caso: planejamento e métodos. 2.ed. Rio de janeiro: Bookman, 2001. 